\title{
Female Agassiz's desert tortoise activity at a wind energy facility in southern California: The influence of an El Niño event
}

\author{
Josh R. Ennen ${ }^{1,2}$, Kathie Meyer ${ }^{3}$, Jeffrey Lovich ${ }^{1^{*}}$ \\ ${ }^{1}$ US Geological Survey, Southwest Biological Science Center, Flagstaff, USA; *Corresponding Author: jeffrey lovich@usgs.gov \\ ${ }^{2}$ Department of Biology, Maryville College, Maryville, USA; josh.ennen@maryvillecollege.edu \\ ${ }^{3}$ US Department of Agriculture, Forest Service, San Bernardino National Forest, USA; kpmeyer@fs.fed.us
}

Received 2 December 2011; revised 30 December 2011; accepted 13 January 2012

\begin{abstract}
We compared spring-summer activity of adult female Agassiz's Desert Tortoises (Gopherus agassizii) among three consecutive years $(1997,1998$, and 1999) that differed dramatically in winter rainfall and annual plant production at a wind energy facility in the Sonoran Desert of southern California. Winter rainfall was approximately $71 \%$, $190 \%$, and $17 \%$ of the long-term average (October-March $=114 \mathrm{~mm}$ ) for this area in water years (WY) 1997, 1998, and 1999, respectively. The substantial precipitation caused by an El Niño Southern Oscillation (ENSO) event in WY 1998 produced a generous annual food plant supply $\left(138.2 \mathrm{~g}\right.$ dry biomass $\left./ \mathrm{m}^{2}\right)$ in the spring. Primary production of winter annuals during below average rainfall years (WY 1997 and WY 1999) was reduced to 98.3 and $0.2 \mathrm{~g} / \mathrm{m}^{2}$, respectively. Mean rates of movement and mean body condition indices (mass/length) did not differ significantly among the years. The drought year following ENSO (WY 1999) was statistically similar to ENSO in every other measured value, while WY 1997 (end of a two year drought) was statistically different from ENSO using activity area, minimum number of burrows used, and percentage of nonmovements. Our data suggest that female $G$. agassizii activity can be influenced by environmental conditions in previous years.
\end{abstract}

Keywords: Activity; Body Condition Index; Agassiz's Desert Tortoise; El Niño; ENSO; Precipitation

\section{INTRODUCTION}

The term El Niño, has been applied to specific climatic conditions but a single universal definition for the phenomenon is elusive. One such definition is that El Niño occurs when five month running means of sea surface temperature (SST) anomalies in a portion of the Pacific Ocean exceed $0.4^{\circ} \mathrm{C}$ for 6 months or more [1]. When these conditions occur, along with an atmospheric component known as the Southern Oscillation, precipitation in the western United States can be significant.

Changes in productivity caused by El Niño Southern Oscillation (ENSO) events can have significant biological consequences for organisms at multiple trophic levels $[2,3]$, including alterations in behavior, reproductive success, survival [4], and even genetic diversity [5]. For example, during ENSO events, seabirds [6-11] and marine mammals $[12,13]$ are sometimes adversely affected by warmer ocean temperatures that reduce availability of food resources. Conversely, increases in seed banks caused by above-average precipitation during ENSO events are suspected to increase rodent populations in Chile $[14,15]$. However, ENSO events were reported to have both positive and negative influences on some turtle species. Galapagos Tortoises (Chelonoidis nigra) gained mass during an ENSO event, but also experienced 80\% egg mortality associated with fungal infections [16]. Likewise, ENSO events influence the probability of remigration and annual reproduction of Leatherback Seaturtles (Dermochelys coriacea) depending on which phase of ENSO (i.e., warm or cool) is occurring [17]. For Agassiz's Desert Tortoises (Gopherus agassizii) that inhabit arid landscapes where resource abundance is unpredictable both spatially and temporally, the species should benefit from increased forage resulting from increases in precipitation associated with ENSO events.

Primary plant production in deserts is closely associated with precipitation, but the timing and quantity of winter precipitation can vary annually, thereby influenceing the germination of spring annuals $[18,19]$. Behavior of G. agassizii is affected by weather patterns, especially precipitation [20,21]. Rainfall influences the behavior of 
G. agassizii directly by creating opportunities for water intake [22] and indirectly by altering the amount of forage available to them, which can result in differences in annual activity patterns [20,23]. The degree to which forage resources are limited should determine the amount of energy available for G. agassizii [24]. Furthermore, the ability of an animal to sequester energy reserves ultimately dictates survival and reproductive success. Energy can be allocated to storage, self-maintenance, growth, reproduction, locating mates, and/or finding shelter, nesting, or basking sites $[25,26]$. Selection should favor individuals that effectively manage and allocate energy requirements in light of seasonal resource availability [27]. G. agassizii needs to be able to harvest and allocate resources under environmental conditions that fluctuate spatially, seasonally, and annually.

Reference [20] found that G. agassizii at two different sites in California reduced their annual activity dramatically in a "drought" year compared to a "productive" year, presumably to conserve energy or maintain water balance during the dryer year. Given that ENSO can bring increased rainfall to the Southern California Desert Region, these events augment opportunities for female G. agassizii to increase their rates of water intake, thereby stabilizing osmotic and ionic concentrations [28,29], and potentially their energy use. Because ENSO events can have dramatic impacts on some organisms and very little is published on the inter-year variation in activity patterns of $G$. agassizii, we investigated the relationship between Desert Tortoise activity patterns, annual plant biomass quantity, and rainfall patterns. Our study animals were first subjected to a two year drought ending in 1997, followed by the large ENSO event in 1998 [30], and then a drought in 1999 (Figure 1). Given this opportunity, we analyzed various components of annual activity including activity area size, rate of travel, minimum number of burrows used, and proportion of time individuals had no movement between captures. We also calculated a body condition index for individuals in each year to examine the relationship between activity levels and body condition in the context of resource availability.

\section{METHODS}

\subsection{Study Site}

Our study site, Mesa, was located in the San Gorgonio Pass, Riverside County, California, USA, about $13 \mathrm{~km}$ northwest of Palm Springs $\left(\approx 33.951^{\circ} \mathrm{N}, 116.665^{\circ} \mathrm{W}\right)$. The land is administered by the US Bureau of Land Management and leased in part to a private company for production of wind-energy. As a result of this land-use, a significant portion of Mesa was disturbed by dirt roads and anthropogenic structures (e.g., wind turbines, electrical transformers). Approximately half of Mesa's boundary encompasses rugged, mountainous terrain in the foothills of the San Bernardino Mountains characterized by steep, sometimes rocky slopes. The remaining portion consists of more gently rolling hills interlaced with dry washes. Additional details of the study site and its vegetation are provided by [31].

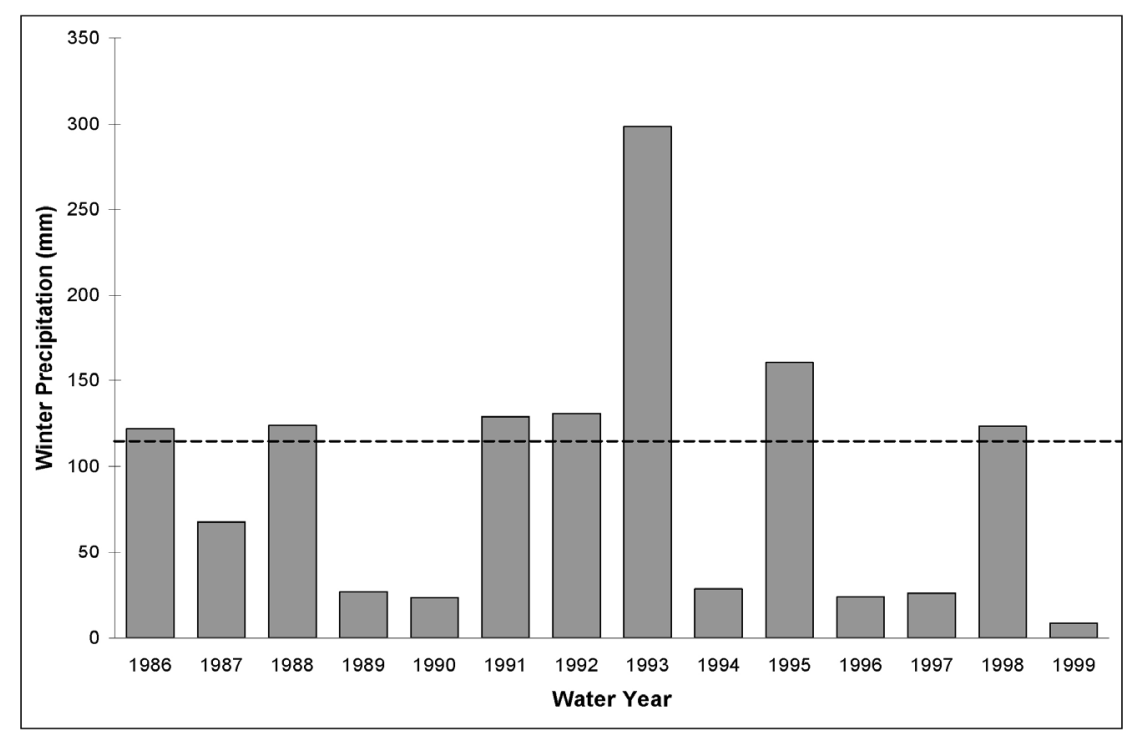

Figure 1. Annual winter (October-March) precipitation totals (bars) and long-term mean (dashed line) for Palm Springs, California from 1986-1999 adapted from [42]. The mean winter precipitation was calculated from 69 years of data. Despite the proximity of Mesa to Palm Springs there is a significant decrease in precipitation at the latter due to a pronounced rain-shadow effect, particularly evident in 1998. 


\subsection{Data Collection}

This study was coincident with an investigation of geographic variation and environmental determinants of reproductive output and demography in female G. agassizii $[32,33]$. Because individuals were monitored primarily to examine egg production, they were handled frequently during the egg-laying season (April-July), when above ground activity is high. Typical handling involved transporting individuals to an on-site $\mathrm{X}$-radiograph station, where they were processed (X-radiographed and weighed) and returned to the capture location. Although we were unable to test for behavioral modifications resulting from regular handling of the study animals, our protocol was consistent among individuals and years.

Beginning in March 1997, we attached radio transmitters (Advanced Telemetry Systems, Inc.) to all adult female G. agassizii (midline carapace length $>180 \mathrm{~mm}$ ) encountered during searches with an attachment technique similar to that described by [34]. We acquired new individuals as our study progressed, thus slightly increasing our sample size each year. However, we only included individuals radio-tagged for the entire April August sample period each year in analyses to standardize comparisons among years. Because of the importance of the precipitation cycle to germination and foraging activity, we refer to study years using the standard definition of a water year - a 12-month period, October 1 through September 30, designated by the calendar year in which it ends. Thus, the year ending September 30, 1997, constitutes water year (WY) 1997.

We located individuals at weekly intervals and recorded several measurements. For every recapture, we recorded GPS coordinates, which were used to calculate activity area (AA) and movement rates. AA was defined as the two-dimensional space used by individuals during the majority of their active season (April through August) and was calculated as a $100 \%$ MCP (minimum convex polygon) using CALHOME [35]. Distance traveled between successive capture points was also calculated in CALHOME using the minimum linear distance (MLD) traveled between sequential observations [36,37]. MLDs were converted into movement rates by dividing meters traveled since each previous capture by elapsed hours between the last capture to obtain a standardized estimate of rate $(\mathrm{m} / \mathrm{hr})$. When we analyzed these data, we excluded cases of non-movement (when an individual was found at the same location in two sequential observations) in our comparisons of rates between years because using observations when individuals do not move violates the assumption of independence in data required for statisticcal analysis [38]. Using the non-movement data, we calculated another value that represented the number of observations when individuals were located at the same location in a sequential capture as a means of measuring degree of inactivity in a given year, and then made comparisons across years.

We recorded burrow usage for each individual. Tortoises spend large amounts of time in burrows, and the spatial arrangement of burrows can play a role in determining the size and shape of an activity area [20]. We counted the minimum number of burrows used by each individual in each year by tallying the number of unique burrows used by each individual. We also calculated a general body condition index (COND) for each individual, each year, as a ratio of mean annual body mass (the mean of body mass measurements taken during multiple recaptures in a given year) divided by midline carapace length measured as $\mathrm{g} / \mathrm{cm}$. Using this ratio a tortoise with forage and water resources available to it might be expected to have a higher $\mathrm{g} / \mathrm{cm}$ COND than the same individual in another year if it had lower resource availability, as demonstrated by [39] using volume-based measures. Like others [40], we recognize that there are limitations with this measure, especially when used to assess disease status of G. agassizii [41]. COND was calculated using 487 mass measurements (114 in 1997, 188 in 1998, and 185 in 1999).

To quantify monthly precipitation (almost exclusively rainfall), we recorded monthly totals at Mesa using a rain gauge centrally located at our study site (filled partially with mineral oil to prevent evaporation). Regional longterm average winter rainfall (October-March $=114 \mathrm{~mm}$ ) was calculated based on 69 years data [42] for nearby Palm Springs, CA to compare with monthly rainfall we recorded at Mesa. We refer to WY 1997, WY 1998, and WY 1999 as drought followed by drought (DFD), ENSO, and drought following ENSO (DFE), respectively, from this point forward. Southern Oscillation Index values [43] confirmed October-March climatic conditions with values of 3.37, -18.88 and 11.63 for the years 1997, 1998 and 1999, respectively; ENSO conditions are often characterized by sustained negative values.

During the study, we measured above-ground biomass of annual plants during the period of perceived peak availability in spring. We randomly located 10 areas to create $100 \mathrm{~m}$ transects and collected annual plant clippings in four quadrats per transect. Half of the quadrats were located in the inter-space between shrubs, and the others were located under the canopy of a nearby shrub. Quadrats were $20 \times 50 \mathrm{~cm}$ in area. Plant samples were dried in an oven at $55^{\circ} \mathrm{C}$ for 48 hours and then weighed immediately. Estimates of biomass were calculated using mean mass of annual plants per quadrat per transect after correcting for percent canopy of perennial shrubs (using measurements of percent canopy cover along the same transect). Because a fire burned approximately $79 \%$ of the 345 ha study area prior to the beginning of our re- 
search in 1995, separate biomass estimates were calculated for transects in burned and unburned areas.

\subsection{Statistical Analysis}

We used a mixed model analysis of variance (ANOVA) with individuals nested within years as a random effect and years as a fixed effect for all statistical comparisons. All data were normally distributed except for minimum number of burrows used, which only had one cell that did not meet normality. This issue was mostly due to the small sample size within that cell; therefore, we elected to use a parametric test and relied on the robustness of the ANOVA. We used post-hoc tests (i.e., Tukey's Honestly Significant Difference [HSD] test) to determine differences between various pairwise combinations of years. All statistical analyses were conducted using JMP version 8.0 (SAS Institute Inc., 2008) at an alpha level of 0.05.

\section{RESULTS}

\subsection{Weather and Productivity}

Precipitation at Mesa totaled 81, 217 and $19 \mathrm{~mm}$ in the WY 1997, WY 1998, and WY 1999 winter growing seasons (October-March), respectively, values that were greater than nearby Palm Springs winter precipitation totals (Figure 1) due to a strong rain-shadow effect in the area (Lovich and Daniels 2000). During our study, precipitation totals were $71 \%, 190 \%$, and $17 \%$ of the longterm winter average $(114 \mathrm{~mm})$ and resulted in different amounts of spring annual plant biomass among the years Table 1.

\subsection{Movement, Activity, and Condition}

Activity area, percent of observations with no movement, and minimum number of burrows used were based upon a total of 522 relocations (120 in 1997, 190 in 1998, and 212 in 1999). AA differed among years $(\mathrm{F}=3.49$, $\mathrm{df}$ $=2, p=0.05$ ) with the mean for DFD being significantly less than the mean for ENSO using Tukey's HSD test Table 2. Mean rate of movement did not differ among years $(\mathrm{F}=0.39, \mathrm{df}=2, p=0.69$; Table 2 . However, the means for minimum number of burrows used were significantly different among years $(\mathrm{F}=7.07$, $\mathrm{df}=2, p=$ 0.003 ) with the mean for DFD being significantly less than the mean for DFE and ENSO using a Tukey's HSD test Table 2. The proportion of observations where tortoises were found in the same location as the previous week (i.e., no movement) was statistically different among years $(\mathrm{F}=3.87$, $\mathrm{df}=2, p=0.03)$ with the mean for ENSO being significantly less than the mean for DFD using a Tukey's HSD test Table 2. Mean COND values were not significantly different among years $(\mathrm{F}=2.58$, df $=2, p=0.10)$.
Table 1. The precipitation and productivity at a Desert Tortoise study site in Riverside Co., California for a three-year period encompassing a drought year following a drought (DFD), an El Niño (ENSO event) year, and a drought following ENSO year (DFE). For spring dry biomass, the values represent mean, standard error, and sample size.

\begin{tabular}{cccc}
\hline & \multicolumn{3}{c}{ Category } \\
\cline { 2 - 4 } & DFD & ENSO & DFE \\
\hline Winter precipitation $(\mathrm{mm})$ & 81 & 217 & 19 \\
Spring dry biomass $\left(\mathrm{g} / \mathrm{m}^{-2}\right)$ & $98.3 \pm 16.1$ & $138.2 \pm 32.4$ & $0.2 \pm 0.1(36)$ \\
\hline
\end{tabular}

Table 2. Number of individuals and movement and activity characteristics of Gopherus agassizii at our study site (Mesa) over a three-year period, which encompassed an El Niño (ENSO event), moderate precipitation (DFD), and drought (DFE) years. Values represent means and standard errors. Asterisks represent a significant difference among category and categories not connected by the same letter are significantly different.

\begin{tabular}{|c|c|c|c|}
\hline & \multicolumn{3}{|c|}{ Category } \\
\hline & DFD & ENSO & DFE \\
\hline No. of individuals & 7 & 11 & 12 \\
\hline Activity Area (ha)* & $2.4 \pm 0.8^{\mathrm{A}}$ & $11.1 \pm 2.6^{\mathrm{B}}$ & $6.9 \pm 1.4^{\mathrm{AB}}$ \\
\hline $\begin{array}{l}\text { Mean rate of movement } \\
\qquad(\mathrm{m} / \mathrm{hr})\end{array}$ & $1.0 \pm 0.2$ & $1.1 \pm 0.1$ & $0.9 \pm 0.1$ \\
\hline $\begin{array}{l}\text { Minimum number of } \\
\text { burrows used* }\end{array}$ & $4.6 \pm 0.5^{\mathrm{A}}$ & $7.3 \pm 0.4^{\mathrm{B}}$ & $7.3 \pm 0.6^{\mathrm{AB}}$ \\
\hline$\%$ no movements* & $32.1 \pm 5.9^{\mathrm{A}}$ & $14.6 \pm 3.1^{\mathrm{B}}$ & $21.9 \pm 4.2^{\mathrm{AB}}$ \\
\hline Body condition $(\mathrm{g} / \mathrm{cm})$ & $107.2 \pm 2.9$ & $119.0 \pm 2.5$ & $113.7 \pm 2.5$ \\
\hline
\end{tabular}

\section{DISCUSSION}

\subsection{Gopherus agassizii Movement and Activity}

The desert is an unpredictable environment where resource availability and abundance fluctuate spatially and temporally because of differences in the timing and amount of precipitation. Therefore, selection should favor plasticity in foraging behaviors in G. agassizii, thus allowing individuals to maximize energetic gain under widely fluctuating conditions by altering foraging seasonally and annually. For example, reference [44] presented several scenarios experienced by Desert Tortoises that would undoubtedly influence their foraging behavior and ultimately movement behaviors. First, when little or no new germination occurs (e.g., drought conditions), foraging opportunities are very limited and would only include dry grasses/forbs and cacti. Second, in low to average rainfall years (e.g., moderate conditions), some annuals germinate with a small number of these being common and only a few species occurring uniformly across the landscape. Finally, during years of substantial precipitation (e.g., ENSO), G. agassizii are presented with a diverse array of choices because annual plant diversity increases dramatically, which would allow individuals to be more selective in their dietary choices. 
From April 1997 through August 1999, female G. agassizii at Mesa experienced wide fluctuations in resource availability. For example, annual plant production patterns corresponded with winter precipitation levels at Mesa with a large amount of annual plant biomass being produced in ENSO, a lesser amount produced in DFD, and virtually no annuals produced in DFE Table 1. Several tortoise behaviors are reported to be correlated with availability of annuals including movement, home-range size, and time above ground [20,21], suggesting that $G$. agassizii modify their movement and activity behavior based on resource availability. Presumably, in response to this resource fluctuation, female G. agassizii at Mesa altered certain aspects of their behavior by increasing their activity area, minimum number of burrows used, and moving more often (e.g., less cases of non-movement between recaptures) during ENSO when compared to DFD.

Usually during drought or poor germination conditions, G. agassizii reduce activity or become inactive, presumably to conserve energy and water reserves $[20,23,45]$. Similarly in other tortoises like Geochelone yniphora, larger home ranges were maintained in months when annual forage is available [46] but reduced activity was observed later in the year when forage was not available (or was dry). Therefore, if forage abundance of the current year is the sole motivator for G. agassizii movements and activities, individuals at Mesa would have reduced their activity levels in the DFE year compared to the DFD and ENSO condition, consistent with the findings of [20], because less forage was available in the DFE year.

The incongruence in behavioral responses to precipitation between Mesa and the study sites of [20] could be explained by several hypotheses. First, even in drought years there is some germination at Mesa due to the proximity of the site to more coastally-influenced (wetter) weather conditions [31]. Farther into the desert, at the study sites of reference [20], the authors reported that precipitation in one year (WY 1996) was so low that "annuals were completely absent from both study areas, and perennials were brown and desiccated". We have never observed conditions that severe at Mesa during our studies from 1995-2011. Thus, female tortoises had some forage at Mesa, even in years that received substantially less than the long-term average amount of precipitation. Second, female G. agassizii at Mesa may be forced to move more often or for greater distances during drought conditions, perhaps searching for more widely dispersed or limited forage species [44]. However, the second hypothesis only explains the relatively higher values for DFE but not the low values observed for DFD. Third, the high activity and movement observed in 1999 may have been influenced by the ENSO event of the previous year. Energy reserves created because of the increased avai- lability of food, which resulted in a higher but not significantly different COND value, may have fueled activity even under low rainfall conditions (see Body Condition Indices, Section 4.2). Reference [47] suggested that growth in Desert Tortoises could be decoupled from current year energy availability, relying more on previously stored fat. It is possible that these stores could fuel greater activity as well. Although ENSO effects may persist for months or even years, the consequences of the ENSO event are best elucidated by long-term, rather than short-term studies. However, our results representing a short-term study suggest the possibility of an ENSO effect one year later.

In WY 1997 or DFD, the opposite situation occurred from DFE. The year before WY 1997 received little winter precipitation (Figure 1) and germination. Therefore, individuals at Mesa entering WY 1997 were already stressed, which negatively influenced movement and activity behaviors. This shows another example of movement and activity of G. agassizii being influenced by environmental conditions in the previous year and not just related to precipitation and productivity of the current year.

\subsection{Body Condition Indices}

It is somewhat perplexing that mean COND values did not differ significantly across such a wide range of environmental conditions despite the fact that means followed our expectations of higher values during ENSO and lower values during DFD and DFE Table 2. Our sample sizes may have been inadequate to detect a difference at an alpha of 0.05 . If alpha was increased to 0.10 (the probability value calculated for our test comparing COND values) statistical power would be increased. However, this increases the chance of making a Type I error (rejecting our null hypothesis that there was no difference in mean COND among years when it is true) while decreasing the chance of making a Type II error (accepting our null hypothesis that there is no difference in mean COND among years when it is false). Another reason why we were unable to detect a difference in mean COND values may be related to limitations of weight-to-length condition indices due to differences in individual reproductive status (presence or absence of eggs), dietary condition (recently fed vs. unfed), and availability of free water in the environment. Desert Tortoises can lose $40 \%$ of body weight during droughts or gain $33 \%$ of body weight by drinking when free water is available [48].

\subsection{Conclusions}

G. agassizii has a suite of survival tactics, including extreme anhomeostasis [28], low field metabolic rates 
[47], the ability to spend inhospitable periods in burrows $[20,49]$, the ability to withstand extreme fluid imbalances [50], the capacity to react quickly and take advantage of rainfall [22,28], and likely the ability to adjust foraging strategies to fit current environmental conditions [44]. The capacity to remain flexible through adaptations and exaptations [51] in an unpredictable environment allows G. agassizii to continue to persist in the harsh desert landscape. Our data suggest that, at least in some years, movement and behavior must be considered in the context of winter rainfall and annual plant biomass of both the current year and previous year. ENSO years may be important to tortoises, providing opportunities to remain active in subsequent years when resources are scarce.

\section{ACKNOWLEDGEMENTS}

We thank H. Avery, B. Henen, and O. Oftedal for comments given to us early in development of this manuscript. B. Boarman, J. Duda, T. Esque, D. Kisner, K. Pease and M. Znari provided useful feedback on earlier drafts of this manuscript. A. Atkinson provided much appreciated statistical advice and T. Zmudka provided GIS support. Numerous volunteers assisted in data collection: A. Clandenning, R. Daniels, J. Hayes, C. Hisaoka, N. Hutchins, J. LaPoint, D. Mitchell, S. McKenzie, M. Toppe, J. Pennycook, and many others who are not mentioned here. This research was supported in part by the US Geological Survey, Western Ecological Research Center, Joshua Tree National Park, and the Bureau of Land Management, California Desert District. Analysis and manuscript preparation was supported by the California Energy Commission, Research Development and Demonstration Division, Public Interest Energy Research program (contract \# 500-09-020). Research was conducted under permits from the U.S. Fish and Wildlife Service, the California Department of Fish and Game and the U.S. Bureau of Land Management. Special thanks to Al Muth for providing accommodations at the Philip L. Boyd Deep Canyon Research Center of the University of California, Riverside, during the development of the manuscript. Any use of trade, product, or firm names is for descriptive purposes only and does not imply endorsement by the US Government.

\section{REFERENCES}

[1] Trenberth, K.E. (1997) The definition of El Niño. Bulletin of the American Meteorological Society, 78, 2771-2777. http://echorock.cgd.ucar.edu/cas/Trenberth/trenberth.pape rs/defnBAMS.pdf

[2] Stapp, P., Polis, G.A. and Sanchez, F.P. (1999) Stable isotopes reveal strong marine and El Niño effects on island food webs. Nature, 401, 467-469. doi:10.1038/46769

[3] Holmgren, M., Scheffer, M., Ezcurra, E., Gutiérrez, J.R. and Mohren, G.M.J. (2001) El Niño effects on the dynamics of terrestrial ecosystems. Trends in Ecology and Evolution, 16, 89-94. doi:10.1016/S0169-5347(00)02052-8

[4] Barber, R.T. and Chavez, F.P. (1983) Biological cones- quences of El Niño. Science, 222, 1203-1210. doi:10.1126/science.222.4629.1203

[5] Fauvelot, C., Cleary, D.F.R. and Menken, S.B.J. (2006) Short-term impact of disturbance on genetic diversity and structure of Indonesian populations of the butterfly Drupadia theda in East Kalimantan. Molecular Ecology, 18, 2069-2081. doi:10.1111/j.1365-294X.2006.02920.x

[6] Anderson, D.J. (1989) Differential responses of boobies and other seabirds in the Galapagos to the 1986-1987 El Niño-Southern Oscillation event. Marine Ecology Progress Series, 53, 209-216. doi:10.3354/meps052209

[7] Boersma, P.D. (1998) Population trends of the Galapagos Penguin: Impacts of El Niño and La Niña. The Condor, 100, 245-253. doi:10.2307/1370265

[8] Boersma, P.D. (1998) The 1997-1998 El Niño: Impacts on penguins. Penguin Conservation, 11, 10-11, 19.

[9] Paredes R. and Zavalaga, C.B. (1998) Overview of the effects of the El Niño 1997-1998 on Humboldt Penguins and other seabirds at Punta San Juan, Peru. Penguin Conservation, 11, 5-7.

[10] Valle, C.A., Cruz, F., Cruz, J.B., Merlen, G. and Coulter, M.C. (1987) The impact of the 1982-1983 El NiñoSouthern Oscillation on seabirds in the Galapagos Islands, Ecuador. Journal of Geophysical Research, 92, 1443714444. doi:10.1029/JC092iC13p14437

[11] Wilson, U.W. (1991) Responses of three seabird species to El Niño events and other warm episodes on the Washington Coast, 1979-1990. The Condor, 93, 853-858.

[12] Guinet, C., Jouventin, P. and Georges, J.Y. (1994) Longterm population changes of fur seals Arctocephalus gazella and Arctocephalus tropicalis on subantarctic (Crozet) and subtropical (St. Paul and Amsterdam) islands and their possible relationship to El Niño Southern Oscillation. Antarctic Science, 6, 473-478.

[13] Limberger, D., Trillmich, F., Kooyma, G. L. and Masluf, P. (1983) Reproductive failure of fur seals in Galapagos and Peru in 1982-1983. Tropical Ocean Atmospheric Newsletter, 21, 16-17.

[14] Jaksic, F.M., Silva, S.I., Meserve, P.L. and Gutierrez, J.R. (1997) A long-term study of vertebrate predator responses to an El Niño (ENSO) disturbance in Western South America. Oikos, 78, 341-354. doi:10.2307/3546302

[15] Lima, M. and Jaksic, F.M. (1998) Delayed density-dependant and rainfall effects on reproductive parameters of an irruptive rodent population in semiarid Chile. Acta Theriologica, 43, 225-234.

[16] Márquez, C., Wiedenfeld, D.A., Naranjo, S. and Llerena, W. (2008) The 1997-1998 El Niño and the Galapagos tortoises Geochelone vandenburghi on alcedo volanco, galapagos. Galapagos Research, 65, 7-10.

[17] Saba, V.S., Santidrián-Tomillo, P. Reina, R.D., Spotila, J.R., Musick, J.A., Evans, D.A. and Paladino, F.V. (2007) The effect of the El Nino Southern Oscillation on the reproductive frequency of eastern Pacific leatherback turtles. Journal of Applied Ecology, 44, 395-404. doi:10.1111/j.1365-2664.2007.01276.x

[18] Beatley, J.C. (1974) Phenological events and their envi- 
ronmental triggers in Mojave Desert ecosystems. Ecology, 55, 856-863. doi: $10.2307 / 1934421$

[19] Bowers, J.E. (2005) El Niño and displays of springflowering annuals in the Mojave and Sonoran deserts. Journal of the Torrey Botanical Society, 132, 38-49. doi:10.3159/1095-5674(2005)132[38:ENADOS]2.0.CO;2

[20] Duda, J.J., Kryzysik, A.J. and Freilich, J.E. (1999) Effects of drought on desert tortoise movement and activity. Journal of Wildlife Management, 63, 1181-1192. doi: $10.2307 / 3802836$

[21] Ernst, C.H., Lovich, J.E. (2009) Turtles of the United States and Canada. 2nd Edition, Johns Hopkins University Press, Baltimore.

[22] Medica, P.A., Bury, B.R. and Luckenbach, R.A. (1980) Drinking and construction of water catchments by the desert tortoise, Gopherus agassizii, in the Mojave Desert. Herpetologica, 36, 310-904.

[23] Freilich, J., Burnham, K.P., Collins, C.M. and Garry, C.A. (2000) Factors affecting population assessments of desert tortoises. Conservation Biology, 14, 1479-1489. doi:10.1046/j.1523-1739.2000.98360.x

[24] Henen, B.T. (1997) Seasonal and annual energy budgets of female desert tortoises (Gopherus agassizii). Ecology, 78, 283-296.

[25] Congdon, J.D. (1989) Proximate and evolutionary constraints on energy relations of reptiles. Physiological Zoology, 62, 356-373.

[26] Gibbons, J.W., Greene, J.L. and Congdon, J.D. (1990) Temporal and spatial movement patterns of sliders and other turtles. In: Gibbons, J.W., Ed., Life History and Ecology of the Slider Turtle, Smithsonian Institution Press, Washington, DC, 201-215.

[27] Congdon, J.D., Dunham, A.E. and Tinkle, D.W. (1982) Energy budgets and life histories of reptiles. In: Gans, C., Ed., Biology of the Reptilia, Academic Press, New York, 13, 233-271.

[28] Peterson, C.C. (1996) Anhomeostasis: Seasonal water and solute relations in two populations of the desert tortoise (Gopherus agassizii) during chronic drought. Physiological Zoology, 69, 1324-1358.

[29] Henen B.T., Peterson, C.C., Wallis, I. R., Berry, K.H. and Nagy, K.A. (1998) Effects of climactic variation on field metabolism and water relations of desert tortoises. Oecologia, 117, 365-373. doi: $10.1007 / \mathrm{s} 004420050669$

[30] Changnon, S.A. (2000) El Niño 1997-1998, the climate event of the century. Oxford University Press, New York.

[31] Lovich, J.E. and Daniels, R. (2000) Environmental characteristic of desert tortoise (Gopherus agassizii) burrow locations in an altered industrial landscape. Chelonian Conservation and Biology, 3, 714-721.

[32] Lovich, J.E., Medica, P., Avery, H., Meyer, K., Bowser, G. and Brown, A. (1999) Studies of reproductive output of the desert tortoise at Joshua Tree National Park, the Mojave National Preserve, and comparative sites. Park Science, 19, 22-24.

[33] Lovich, J.E., Ennen, J.R., Madrak, S., Meyer, K., Loughran,
C., Bjurlin, C., Arundel, T., Turner, W., Jones, C. and Groenendaal, G.M. (2011) Effects of wind energy production on growth, demography and survivorship of a desert tortoise (Gopherus agassizii) population in southern California with comparisons to natural populations. Herpetological Conservation and Biology, 6, 161-174. http://www.herpconbio.org/Volume_6/Issue_2/Lovich_et al 2011.pdf

[34] Boarman, W.I., Goodlett, T. and Goodlett, G.C. (1998) Review of radio transmitter attachment techniques for chelonian research and recommendations for improvement. Herpetological Review, 29, 26-33.

[35] Kie, J.G., Baldwin, J.A. and Evans, C.J. (1996) CALHOME: A program for estimating animal homeranges. Wildlife Society Bulletin, 24, 342-344.

[36] Lovich, J.E., Herman, D.W. and Fahey, K.M. (1992) Seasonal activity and movements of bog turtles (Clemmys muhlenbergii) in North Carolina. Copeia, 1992, 11071111. doi: $10.2307 / 1446649$

[37] Nieuwolt, P.M. (1996) Movement, activity, and microhabitat selection in the western box turtle, Terrapene ornata luteola, in New Mexico. Herpetologica, 52, 487495.

[38] O’Connor, M.P., Zimmerman, L.C., Ruby, D.E., Bulova, S.J. and Spotila, J.R. (1994) Home range size and movements by desert tortoises, Gopherus agassizii, in the eastern Mojave Desert. Herpetological Monographs, 8, 6071.

[39] Nagy, K.A., Henen, B.T., Vyas, D.B. and Wallis, I.R. (2002) A condition index for the desert tortoise (Gopherus agassizii). Chelonian Conservation and Biology, $\mathbf{4}$, 425-429.

[40] Hayes, J.P. and Shonkwiler, J.S. (2001) Morphometric indicators of body condition: worthwhile or wishful think? In: Speakman, J.R., Ed., Body Composition Analysis of Animals: A Handbook of Non-Destructive Methods, Cambridge University Press, Cambridge, 8-38.

[41] Jacobson, E.R., Weinstein, M., Berry, K., Hardenbrook, B., Tomlinson, C. and Freitas, D. (1993) Problems with using weight versus carapace length relationships to assess tortoise health. Veterinary Record, 132, 222-223. doi:10.1136/vr.132.9.222

[42] Longpré, C.I. and Hereford, R. (1998) Climate history of the Mojave Desert Region, 1892-1996, including data from 48 long-term weather stations and an overview of regional climate variation. http://mojave.usgs.gov/climate-history/

[43] Australian Government Bureau of Meteorology (2011) http://www.bom.gov.au/climate/current/soihtm1.shtml

[44] Oftedal, O. (2002) Nutritional ecology of the desert tortoise in the Mojave and Sonoran Deserts. In: Van Devender, T.R., Ed, The Sonoran Desert Tortoise, Natural History, Biology, and Conservation, University of Arizona Press and The Arizona-Sonora Desert Museum, Tucson, 194-241.

[45] Nagy, K.A. and Medica, P.A. (1986) Physiological ecology of desert tortoises in southern Nevada. Herpetologica, 42, 73-92. 
[46] Smith, L.L., Robert, B., Joby, M. and Clement, S. (1999) Home range and microhabitat use in the Angonka (Geochelone yniphora) in Madagascar. Chelonian Conservation and Biology, 3, 393-400.

[47] Peterson, C.C. (1996) Ecological energetics of the desert tortoise (Gopherus agassizii): Effects of rainfall and drought. Ecology, 77, 1831-1844. doi: $10.2307 / 2265787$

[48] Henen, B.T. (2002) Energy and water balance, diet, and reproduction of female desert tortoises (Gopherus agassizii). Chelonian Conservation and Biology, 4, 319-329.
[49] Rautenstrauch, K.R., Rager, A.L. and Rakestraw, D.L. (1998) Winter behavior of desert tortoises in southcentral Nevada. Journal of Wildlife Management, 62, 98-104. doi: $10.2307 / 3802267$

[50] Nagy, K.A. (1988) Seasonal patterns of water and energy balance in desert vertebrates. Journal of Arid Environments, 14, 210-210.

[51] Morafka, D.J. and Berry, K.B. (2002) Is Gopherus agassizii a desert-adapted tortoise, or an exaptive opportunist? Implications for tortoise conservation. Chelonian Conservation and Biology, 4, 263-287. 